\title{
RENDIMENTO DE GRÃOS DE TRIGO E SUA RELAÇÃO COM AS DOENÇAS E VARIÁVEIS CLIMÁTICAS EM CAPÃO BONITO DE 1994 A 2001(1)
}

\author{
JOÃO CARLOS FELICIO ${ }^{(2)}$; CARLOS EDUARDO DE OLIVEIRA CAMARGO ${ }^{(2)}$; \\ JAIRO LOPES DE CASTRO ${ }^{(3)}$; ROGÉRIO GERMANI ${ }^{(4)}$
}

\begin{abstract}
RESUMO
A influência do ambiente no rendimento de grãos de genótipos de trigo e sua relação com as doenças causadas pelos fungos causadores da ferrugem-da-folha e das manchas foliares e suas relações com as variáveis climáticas foram avaliadas no período de 1994-2001, no município de Capão Bonito (SP), latitude $24^{\circ} 02^{\prime} \mathrm{S}$, longitude $48^{\circ} 22^{\prime} \mathrm{W}$ e altitude $702 \mathrm{~m}$. A interação genótipos x anos foi altamente significativa revelando que diferenças climáticas anuais tiveram influência direta no rendimento de grãos. Em 1998, o rendimento médio de grãos foi o melhor do período e em 1994, o pior. Os genótipos IAPAR 60, IAC 60, IAC 120 e BR 18 apresentaram maior rendimento de grãos na média dos anos considerados. IAPAR 60 mostrou instabilidade no rendimento de grãos no período. Os genótipos Anahuac, IAC 120, IAC 356, IAC 342 e IAC 373 foram imunes às raças prevalentes do fungo causador da ferrugem-da-folha. Como as manchas foliares foram favorecidas pelas condições climáticas, sua ocorrência foi generalizada no período. As precipitações pluviais de maio foram as que melhor se correlacionaram com o desenvolvimento dessa doença.
\end{abstract}

Palavras-chave: trigo, genótipos, doenças, variáveis climáticas.

\section{ABSTRACT \\ WHEAT GRAIN YIELD AND THE RELATIONSHIP WITH DISEASES AND CLIMATIC VARIATIONS IN CAPÃO BONITO, IN THE PERIOD 1994 TO 2001}

\begin{abstract}
The environmental influence on grain yield and its relationship with leaf rust and leaf spots diseases was evaluated in the period 1994-2001, in Capão Bonito, State of São Paulo, Brazil, 24 $4^{\circ} 02^{\prime}$ S, $48^{\circ} 22^{\prime}$ W e altitude, $702 \mathrm{~m}$. The genotype $\mathrm{x}$ year interaction was highly significant indicating that annual climatic differences have directly affected the grain yield. The averages of grain yield were the highest in 1998 and the lowest in 1994. The genotypes IAPAR 60, IAC 60, IAC 120 and BR 18 showed high grain yield means. IAPAR 60 did not present grain yield stability. The genotypes Anahuac, IAC 120, IAC 356, IAC 342 and IAC 373 are immune to the prevalent races of the fungus causing leaf rust. As the climatic conditions were favorable to the development leaf spot, its occurrence was generalized. Rainfall in May showed the best correlation with the occurrence of leaf spots.
\end{abstract}

Key words: wheat, genotypes, diseases, climatic variation.

( $\left.{ }^{1}\right)$ Recebido para publicação em 11 de dezembro de 2002 e aceito em 29 de janeiro de 2004.

$\left({ }^{2}\right)$ Instituto Agronômico (IAC), Centro de Análise e Pesquisa Tecnológica dos Agronegócios de Grãos e Fibras, Caixa Postal 28, 13001-970 Campinas (SP). E-mail jfelicio@iac.sp.gov.br; ccamargo@iac.sp.gov.br

( $\left.{ }^{3}\right)$ Pólo Regional de Desenvolvimento Tecnológico dos Agronegócio do Sudoeste Paulista (APTA), Caixa Postal 62, 18300-000 Capão Bonito (SP).

$\left({ }^{4}\right)$ Embrapa Agroindústria de Alimentos, 23020-470 Rio de Janeiro (RJ). E-mail: germani@ctaa.embrapa.br 


\section{INTRODUÇÃO}

O rendimento de grãos por unidade de superfície constitui o indicador universal empregado para ponderar os efeitos do ambiente e a tecnologia na produtividade de uma cultivar. O potencial de rendimento para um determinado ambiente pode ser estimado de diversas maneiras. Os experimentos de avaliação, realizados sistematicamente ao longo de uma série de anos, permitem quantificar as tendências que ocorrem no aumento do potencial das cultivares, como conseqüência do progresso genético e suas interações com os níveis tecnológicos empregados no manejo desses experimentos (DiAZ e ABADIE, 1998).

A duração dos subperíodos de desenvolvimento de trigo está relacionada com variáveis ambientais, tais como precipitações pluviais, temperatura e o comprimento do dia. Associado a isso, tem-se a variável genotípica (cultivar) e as interações entre elas (genótipos-ambientes). Em cada uma dessas etapas, as condições ambientais assumem grande importância. Dessa forma, o manejo da cultura devese ajustar ao período critico, procurando adequá-lo de acordo com as épocas de semeadura e a população de plantas para obter maior disponibilidade de recursos do ambiente e consequentemente, proporcionar maior produção (RODRIGUES, 2000).

Avaliando o comportamento de genótipos de trigo no Vale do Paranapanema (SP), Felicio et al. (1993) observaram que a interação anos x cultivares no período 1985-1991, somente não foi significativa para a cultivar PAT 72247, posto que no cultivo de sequeiro a produção está sempre mais associada às condições climáticas anuais que as outras variáveis.

Felicio et al. (2000) demostraram que os genótipos de trigo apresentaram comportamento regional diferenciado quanto ao rendimento de grãos, com interação significativa entre anos $x$ locais, nas condições de sequeiro, ocorrendo diferenças acentuadas no rendimento de grãos entre Maracaí (Zona A) e Itapeva (Zona B).

Segundo Picinini e Fernandes (2000) devido ao complexo de doenças existente hoje na cultura de trigo, tornou-se muito difícil a incorporação de resistência genética para todas as enfermidades. No melhoramento, a incorporação da resistência aos fungos denominados biotróficos (ferrugens e oídios), tem obtido sucesso, pois a resistência é, na maioria das vezes, governada por poucos genes. Entretanto, para os fungos necrotróficos, como os causadores das "manchas foliares", a resistência genética é, aparentemente, governada por muito genes; nesse caso, o sucesso tem sido limitado.
As perdas na cultura do trigo causadas pelas doenças são relativamente elevadas e, de acordo com Picinini e Fernandes (1995), em 12 anos de experimentação a cultura do trigo registrou uma perda anual média de $44,61 \%$, eqüivalendo a $1.152 \mathrm{~kg}$ de grãos por hectare. DiAZ DE ACKERMANN et al. (1998) verificaram que no Uruguay, em 1977, ano em que o nível de infecção por manchas foliares, fusarioses e ferrugem-da-folha foi superior à média do período 1976-1996, a diferença no rendimento nacional esperado e o observado chegou a ser de $42 \%$. O controle desses fungos causadores de manchas foliares tem sido eficiente com o emprego de fungicidas (Picinini e FERNANDES, 2000).

BRAMMER et al. (2000) revelam que desde o inicio dos anos 70, melhoristas do Centro Internacional de Milho e Trigo-CIMMYT têm-se concentrado no tipo de resistência de progresso lento da ferrugem. A cultivar apresenta uma resposta suscetível, mas a enfermidade avança mais lentamente do que em uma cultivar-testemunha suscetível. A eficiência desse progresso pode ser intensificada através de outros genes que influenciam o fenômeno. O gene Lr 34 por si só determina o progresso lento da enfermidade.

Este trabalho visou avaliar o rendimento de grãos de trigo e sua relação com as doenças, sobretudo as causadas por fungos biotróficos e necrotróficos e as variáveis climáticas da região de Capão Bonito (SP).

\section{MATERIAL E MÉTODOS}

O experimento foi realizado no Pólo Regional de Desenvolvimento dos Agronegócios do Sudoeste Paulista, no município de Capão Bonito, Estado de São Paulo, Zona tritícola B, em cultivo do trigo de sequeiro (Instituto Agronômico, 1999).

Foram avaliados 36 genótipos de trigo descritos na tabela 1. O delineamento experimental utilizado foi o de blocos ao acaso, com quatro repetições. As semeaduras foram efetuadas sempre no primeiro decêndio do mês de abril nos anos de 1994 a 2001. Novos genótipos promissores foram incluídos nos experimentos visando manter sempre o número de 20 por ano. As cultivares IAC 350, IAC 24, IAC 60, IAC 120, IAC 289 , IAC 287, BR 18 e IAPAR 60 foram estudadas em todos os experimentos semeados no período considerado. As parcelas foram compostas por seis linhas de $3 \mathrm{~m}$ de comprimento, com espaçamento de 0,20 $\mathrm{m}$ entre si, e separação lateral de $0,60 \mathrm{~m}$ entre parcelas. Procedeu-se a semeadura com 60 sementes por metro linear de sulco, realizando-se a colheita na área total das parcelas, ou seja, $3,6 \mathrm{~m}^{2}$. As plantas foram mantidas livres de competição com plantas daninhas. 
Tabela 1. Relação dos genótipos, genealogia , ciclo, altura, W (força do glúten) e a classificação da qualidade industrial (Q.I.) que compuseram os experimentos de competição de cultivares de trigo, em Capão Bonito no Estado de São Paulo, no período de 1994 a 2001

\begin{tabular}{|c|c|c|c|c|c|}
\hline Genótipos & Genealogia & Ciclo & Altura & $\mathrm{W}$ & Q.I. ${ }^{(1)}$ \\
\hline & & & $\mathrm{cm}$ & $10-{ }^{4} \mathrm{~J}$ & \\
\hline IAC 227 & CNT 9/BH1146 & Precoce & 100 & 172 & Brando \\
\hline IAC 231 & IRN 641-70/BH 1146 & Precoce & 85 & 186 & Brando \\
\hline IAC 287 & $\mathrm{HIM} / \mathrm{COC} / / \mathrm{NAC}$ & Precoce & 80 & 222 & Pão \\
\hline IAC 304 & MIR 808/BOW & Precoce & 75 & 204 & Brando \\
\hline IAC 332 & EMU"S" / IAC67 & Precoce & 75 & 253 & Pão \\
\hline IAC 340 & BH 1146/7C / / IAC 60 & Precoce & 90 & 126 & Brando \\
\hline IAC 354 & BUC"S" / YD / / IAC 67 & Precoce & 85 & 152 & Brando \\
\hline IAC 358 & BOW"S" / IAC 24 & Precoce & 80 & 265 & Pão \\
\hline IAC 372 & NS12-07/VEE & Precoce & 95 & 113 & Brando \\
\hline Panda & IDS1528/S45 / / PARAGUAI 281 & Precoce & 80 & 182 & Brando \\
\hline Anahuac & II 12300/LR64/8156/3/Nortenhõ 67 & Médio & 85 & 297 & Pão \\
\hline BR 18 & D6301/NAI60//WRM/3/CNO*2/CHR & Médio & 85 & 288 & Pão \\
\hline IAC 24 & IAS 51/4/SON64/Y50E / / GTO/2*CIANO & Médio & 80 & 344 & Melhorador \\
\hline IAC 60 & IRN 33-70/MARINGÁ & Médio & 95 & 192 & Pão \\
\hline IAC 120 & IRN 33-70/MARINGA & Médio & 90 & 218 & Pão \\
\hline IAC 289 & KVZ/BUHOS//KAL/BLUEBIRD & Médio & 80 & 255 & Pão \\
\hline IAC 311 & US74-709/NAC & Médio & 85 & 165 & Brando \\
\hline IAC 313 & IAC 17 / PPINTA & Médio & 90 & 165 & Brando \\
\hline IAC 319 & ALD/BH1146//LONDRINA & Médio & 100 & 162 & Brando \\
\hline IAC 342 & NAC/VEE"S" / /IAC 46 & Médio & 85 & 232 & Pão \\
\hline IAC 346 & PF70354/ALD"S" / /YACO"S" /3/IAC 73 & Médio & 90 & 203 & Brando \\
\hline IAC 347 & PF70354/MUS/ /JUP /EMU/3/GJO/4/IAC73 & Médio & 90 & 206 & Brando \\
\hline IAC 348 & TP / /CNO67/NO/3/BB/CNO/4/ZA75/TIM/6/IAC 60 & Médio & 90 & 184 & Brando \\
\hline IAC 350 & 2109.36/SERI & Médio & 95 & 260 & Pão \\
\hline IAC 355 & PFAU /SERI / / BOW"'S" & Médio & 80 & 260 & Pão \\
\hline IAC 356 & BH1146/ /WIN"S" / AA"S" (IV) & Médio & 90 & 132 & Brando \\
\hline IAC 357 & PVN"S' / BOW"S" / / IAC 60 & Médio & 90 & 216 & Pão \\
\hline IAC 359 & JUN/IAC 60 & Médio & 85 & 128 & Brando \\
\hline IAC 360 & PEWEE"S" / / PF7568/BR35/3/IAC 65 & Médio & 75 & 165 & Brando \\
\hline IAC 371 & FUFAN 17/VEE"S" & Médio & 90 & 134 & Brando \\
\hline IAC 373 & $\mathrm{FCT} / / \mathrm{VR} / \mathrm{PAM}$ & Médio & 85 & 240 & Pão \\
\hline IAPAR 28 & KVZ/BUHOS//KAL/BLUEBIRD & Médio & 80 & 277 & Pão \\
\hline OCEPAR 14 & $\begin{array}{l}\text { IAS64 / ALDAN/6/COC/5/PICHON/4/KT54*2/N10B/ } \\
\text { /KT548/3/NAR }\end{array}$ & Médio & 85 & 217 & Pão \\
\hline IAC 370 & BOW / NAC / / VEE/3/BJY & Tardio & 90 & 274 & Pão \\
\hline IAPAR 60 & BJY"S" /JUP//TAN"S" & Tardio & 95 & 223 & Pão \\
\hline OCEPAR 16 & SIS/VEE & Tardio & 90 & 259 & Pão \\
\hline
\end{tabular}

$\left({ }^{1}\right)$ Brando $=W$ de 50 a $<180 ;$ pão $=W$ de 181 a 300 e melhorador $=W>300$. 
Os dados mensais de precipitação pluvial e das temperaturas máximas e mínimas, relativos aos períodos considerados, foram obtidos no posto meteorológico do Pólo Regional de Desenvolvimento dos Agronegócios do Sudoeste Paulista (latitude $24^{\circ} 02^{\prime} \mathrm{S}$, longitude $48^{\circ} 22^{\prime} \mathrm{W}$ e altitude de $702 \mathrm{~m}$ ), no município de Capão Bonito (SP), conforme tabela 2.

Antes da semeadura, a adubação foi feita a lanço, com posterior incorporação ao solo e consistiu na aplicação de 20, 60 e $28 \mathrm{~kg}$.ha ${ }^{-1}$ de $\mathrm{N}, \mathrm{P}_{2} \mathrm{O}_{5}$ e $\mathrm{K}_{2} \mathrm{O}$, respectivamente, de acordo com RAIJ et al. (1996) e com a análise química do solo. Na adubação em cobertura, foram aplicados $40 \mathrm{~kg} \cdot \mathrm{ha}^{-1}$ de N, 20 a 30 dias após a emergência das plântulas. $\mathrm{O}$ ciclo das cultivares foi determinado pelo número de dias decorridos da emergência das plântulas até a maturação. Os genótipos que exibiram ciclo da emergência à maturação de 110-120, 121-130 e acima de 130 dias foram considerados, respectivamente, de ciclo precoce, médio e tardio.

A altura das plantas foi medida em centímetros, no campo, na época de maturação, do nível do solo ao ápice da espiga, com exclusão das aristas, estimando-se a média de diferentes pontos de cada parcela.
Os genótipos foram classificados em classes: trigo brando, trigo pão e trigo melhorador de acordo com as Instruções Normativas n. ${ }^{\circ}$ 7, de 15/8/2001 do Ministério da Agricultura, Pecuária e Abastecimento (BRASIL, 2001), definidas em função das determinações analíticas de Alveografia (força do glúten ), de acordo com o método da AACC . $^{\circ}$ 54-30A e o Falling Number (Número de Queda), determinado pelo método n. ${ }^{\circ}$ 56-81B (AACC, 1995) realizadas na Embrapa Agroindústria de Alimentos, Rio de Janeiro (RJ).

O comportamento das cultivares em relação à ferrugem-da-folha do trigo (Puccinia triticina Erikss., ANIKSTER et al., 1997) foi avaliado em condições naturais de infecção, em planta adulta (estádios 10.1 a 10.5 da escala de Feekes-Large), utilizando a escala modificada de Cobb, empregada por Schramm et al. (1974).

Essa é composta pela porcentagem estimada da área foliar infectada pela doença, acrescida de uma letra simbolizando o tipo de reação: $S=$ suscetível (uredossoro grande, coalescente, sem clorose); MS = moderadamente suscetível (uredossoro médio); $\mathrm{MR}=$ moderadamente resistente (uredossoro pequeno) e $\mathrm{R}$ resistente (uredossoro minúsculo rodeado de áreas necróticas).

Tabela 2. Dados mensais da precipitação pluvial $(\mathrm{mm})$, temperatura máxima e mínima em graus centígrados do período de março a setembro em Capão Bonito (SP), de 1994 a 2001

\begin{tabular}{|c|c|c|c|c|c|c|c|c|}
\hline Meses & 1994 & 1995 & 1996 & 1997 & 1998 & 1999 & 2000 & 2001 \\
\hline & \multicolumn{8}{|c|}{ Precipitação em mm } \\
\hline Março & 76,7 & 117,5 & 66,2 & 1,0 & 58,4 & 21,8 & 108,4 & 114,1 \\
\hline Abril & 61,6 & 108,2 & 62,7 & 68,2 & 65,6 & 57,7 & 2,7 & 26,7 \\
\hline Maio & 31,3 & 53,7 & 13,6 & 63,5 & 47,4 & 34,5 & 26,5 & 150,8 \\
\hline Junho & 33,6 & 49,6 & 62,3 & 163,4 & 45,0 & 49,0 & 7,9 & 144,1 \\
\hline Julho & 36,7 & 43,5 & 34,2 & 21,0 & 31,7 & 62,4 & 34,4 & 72,5 \\
\hline Agosto & 0 & 27,4 & 32,8 & 59,4 & 44,5 & 0 & 85,3 & 59,3 \\
\hline Setembro & 0 & 0 & 131,0 & 30,1 & 96,0 & 126,9 & 129,3 & 66,2 \\
\hline \multirow[t]{2}{*}{ Total } & 239,9 & 401,9 & 402,8 & 406,6 & 421,6 & 352,3 & 388,5 & 633,7 \\
\hline & \multicolumn{8}{|c|}{ Temperatura máxima ${ }^{\circ} \mathrm{C}$} \\
\hline Maio & 23,7 & 23,0 & 22,8 & 22,4 & 22,9 & 22,8 & 23,1 & 22,0 \\
\hline Junho & 22,8 & 22,8 & 21,8 & 21,4 & 20,7 & 19,8 & 23,4 & 22,3 \\
\hline \multirow[t]{2}{*}{ Julho } & 25,0 & 25,1 & 21,0 & 23,1 & 22,3 & 22,5 & 21,0 & 24,0 \\
\hline & \multicolumn{8}{|c|}{ Temperatura mínima ${ }^{\circ} \mathrm{C}$} \\
\hline Maio & 14,1 & 12,5 & 12,5 & 12,0 & 12,0 & 11,1 & 11,5 & 12,3 \\
\hline Junho & 10,4 & 10,6 & 10,1 & 9,5 & 10,0 & 9,7 & 10,9 & 11,8 \\
\hline Julho & 9,6 & 11,3 & 8,4 & 11,0 & 11,1 & 10,6 & 7,8 & 9,7 \\
\hline
\end{tabular}

Fonte: Centro de Pesquisa e Desenvolvimento de Ecofisiologia e Biofísica (IAC). 
As doenças que causam as "manchas foliares" causadas pelo complexo de fungos necrotróficos como Bipolaris sorokiniana, Drechslera tritici repentis, respectivamente, mancha-marrom e mancha-bronzeada, foram avaliadas, com base em uma escala de porcentagem de área foliar infectada, apresentada por Metha (1978).

Avaliou-se o rendimento de grãos, em gramas, pesando-se a produção total de cada parcela, e transformada em quilograma por hectare.

O rendimento de grão, de cada experimento, foi submetido à análise de variância e a comparação das médias, feita mediante o teste de Duncan. Empregou-se também a análise conjunta de experimentos em blocos ao acaso com tratamentos comuns com o ajuste da média final, de acordo com Pimentel-Gomes (1970).

A estabilidade e a adaptabilidade foram avaliadas pelo método proposto por CRUZ et al. (1989), somente para os genótipos que permaneceram fixos nos oito anos estudados, e com base nos coeficientes de cada genótipo em relação ao índice ambiental, considerou-se a possibilidade de se encontrar o genótipo ideal, aquele que apresentou alto rendimento médio de grãos, coeficiente de regressão igual a $1,0(b=1)$ e desvios da regressão igual a zero $\left(\mathrm{s}^{2} \mathrm{~d}=0\right)$.

Correlações foram estimadas entre os dados climáticos mostrados no tabela 2 e a incidência de manchas foliares (Tabela 7).

\section{RESULTADOS E DISCUSSÃO}

A análise conjunta de variância do rendimento médio de grãos dos genótipos avaliados em Capão Bonito, no período de 1994 a 2001, é apresentada na Tabela 3. Observa-se que os efeitos de genótipos e anos, e da interação genótipos $x$ anos foram significativos $(\mathrm{P}<0,01)$. Esses resultados, já demonstrados por Felicio et al. $(1993,2000)$, revelam que os anos foram contrastantes entre si, principalmente ao se considerar as condições climáticas regionais do período, de acordo com os dados da Tabela 2.

Os genótipos também não constituíram um conjunto homogêneo, refletindo essa diferença nos rendimentos de grãos, com reações diferenciadas para as doenças (ferrugem-da-folha e manchas foliares) e principalmente ao ambiente. A significância da interação genótipos $x$ anos foi indicação positiva das diferenças climáticas entre os anos influenciando o rendimento de grãos. Verifica-se também que os coeficientes de variação estão de acordo com os padrões para a experimentação envolvendo genótipos.
Tabela 3. Graus de liberdade (GL), quadrados médios (Q.M) e valor de $\mathrm{F}$ da análise conjunta da produtividade média de grãos $\left(\mathrm{kg} . \mathrm{ha}^{-1}\right)$ de genótipos de trigos e anos em Capão Bonito (SP), no período de 1994 a 2001

\begin{tabular}{lrrr}
\hline Causas da variação & GL & Q.M. & F \\
\hline Genótipos ajustados & 35 & 1191194,81 & $8,18^{* *}$ \\
Anos ajustados & 7 & 30537091,00 & $209,84^{* *}$ \\
Genótipos/anos ajustados & 117 & 389077,95 & $2,67^{* *}$ \\
Genótipos/ano 1994 & 19 & 493733,11 & $2,39^{* *}$ \\
Genótipos/ano 1995 & 19 & 1143284,64 & $7,85^{* *}$ \\
Genótipos/ano 1996 & 19 & 709304,32 & $4,87^{* *}$ \\
Genótipos/ano 1997 & 19 & 571903,59 & $3,93^{* *}$ \\
Genótipos/ano 1998 & 19 & 634893,34 & $4,36^{* *}$ \\
Genótipos/ano 1999 & 19 & 332106,53 & $2,28^{* *}$ \\
Genótipos/ano 2000 & 19 & 382032,37 & $2,62^{* *}$ \\
Genótipos/ano 2001 & 19 & 322949,38 & $2,21^{* *}$ \\
Resíduo & 480 & 145523,72 & \\
\hline C V. (o\%) & & & 17,13
\end{tabular}

C.V. $(\%)$ 17,13

** significativo ao nível de $1 \%$.

O melhor ano para rendimento médio de grãos foi 1998 e o de menor rendimento médio, 1994, respectivamente com $3.322 \mathrm{~kg} \cdot \mathrm{ha}^{-1} \mathrm{e} 1.167 \mathrm{~kg} \cdot \mathrm{ha}^{-1}$. Esses rendimentos estão bem associados às condições climáticas anuais da região. Em 1994, a precipitação pluvial foi a menor do período do estabelecimento da cultura, ou seja, de março a setembro, $239,9 \mathrm{~mm}$ e, em 1998, a maior com 421,6 mm (Tabela 2 ); portanto, esse resultado é indicativo da existência de condições variáveis, de um ano a outro, e bastante contrastante para se testar os genótipos.

Dezesseis genótipos (IAC 227, IAC 231, IAC304, IAC 332, IAC 340, IAC 358, Panda, Anahuac, IAC 311, IAC 313, IAC 319, IAC 346, IAC 347, IAC 348, IAPAR 28 e OCEPAR 14) foram excluídos da experimentação no período (Tabela 4), considerando-se o baixo rendimento médio de grãos, alta suscetibilidade às doenças e a qualidade industrial dos grãos (classe brando).

O genótipo IAPAR 60 apresentou a maior produção média ajustada de grãos $\left(2.738 \mathrm{~kg} \cdot \mathrm{ha}^{-1}\right)$ no período de 1994 a 2001, não diferindo somente dos genótipos BR 18 (2.525 kg.ha-1), IAC 120 (2.576 kg.ha-1) e IAC 60 (2.531 kg.ha- ${ }^{-1}$ também avaliados no mesmo período. IAPAR 60 também não diferiu dos genótipos IAC 340, IAC 319, IAC 347 E OCEPAR 14, apenas avaliados nos anos de 1994 e 1995 e do genótipo IAC 356 avaliado somente no período de 1996 a 2001. 
Tabela 4. Produtividade média de grãos dos genótipos de trigo avaliados individualmente e em conjunto, em condição de sequeiro, na localidade de Capão Bonito (Zona B), no Estado de São Paulo, de 1994 a 2001

\begin{tabular}{lllllll}
\hline Genótipos & 1994 & 1995 & 1996 & 1997 & 1998 & $1999 \quad \begin{array}{c}\text { Média } \\
\text { Ajustada }\end{array}$ \\
\hline
\end{tabular}

\section{Ciclo precoce}

\begin{tabular}{|c|c|c|c|c|c|c|c|c|c|}
\hline IAC 227 & $1.354 \mathrm{~b}-\mathrm{c}$ & $1.819 \mathrm{e}-\mathrm{i}$ & - & - & - & - & - & - & $2.089 \mathrm{~b}-\mathrm{d}$ \\
\hline IAC 231 & - & - & $2.659 \mathrm{~b}-\mathrm{e}$ & $2.347 \mathrm{~b}-\mathrm{e}$ & - & - & - & - & $2.113 \mathrm{~b}-\mathrm{d}$ \\
\hline IAC 287 & $958 \mathrm{~d}-\mathrm{f}$ & $2.208 \mathrm{~b}-\mathrm{h}$ & $2.260 \mathrm{~d}-\mathrm{e}$ & $2.246 \mathrm{c}-\mathrm{e}$ & $2.986 \mathrm{~b}-\mathrm{f}$ & $2.312 \mathrm{~b}-\mathrm{e}$ & 1.517 c-e & $1.850 \mathrm{a}-\mathrm{c}$ & $2.042 \mathrm{~b}-\mathrm{d}$ \\
\hline IAC 304 & $965 \mathrm{~d}-\mathrm{f}$ & $2.027 \mathrm{c}-\mathrm{i}$ & $2.034 \mathrm{e}$ & $2.545 \mathrm{~b}-\mathrm{e}$ & $2.955 \mathrm{~b}-\mathrm{f}$ & - & - & - & $1.938 \mathrm{c}-\mathrm{d}$ \\
\hline IAC 332 & 840 e-f & $2.277 \mathrm{~b}-\mathrm{c}$ & - & - & - & - & - & - & $2.061 \mathrm{~b}-\mathrm{d}$ \\
\hline IAC 340 & $1.645 \mathrm{~b}$ & 2.576 a-e & - & - & - & - & - & - & $2.613 a-b$ \\
\hline IAC 354 & - & - & $2.649 \mathrm{~b}-\mathrm{e}$ & 2.729 a-e & $3.496 \mathrm{a}-\mathrm{b}$ & $2.732 \mathrm{a}-\mathrm{d}$ & $1.802 \mathrm{~b}-\mathrm{d}$ & $1.729 \mathrm{a}-\mathrm{d}$ & $2.355 \mathrm{~b}$ \\
\hline IAC 358 & - & - & $2.027 \mathrm{e}$ & $3.177 \mathrm{a}-\mathrm{b}$ & - & - & - & - & $2.212 \mathrm{~b}-\mathrm{c}$ \\
\hline IAC 372 & - & - & - & - & - & $2.427 \mathrm{~b}-\mathrm{e}$ & $1.861 \mathrm{~b}-\mathrm{d}$ & $1.864 \mathrm{a}-\mathrm{c}$ & $2.326 \mathrm{~b}-\mathrm{c}$ \\
\hline Panda & 847 e-f & $1.514 \mathrm{~h}-\mathrm{i}$ & - & - & - & - & - & - & $1.682 \mathrm{~d}$ \\
\hline \multicolumn{10}{|l|}{ Ciclo médio } \\
\hline Anahuac & $1.201 \mathrm{c}-\mathrm{d}$ & $1.791 \mathrm{e}-\mathrm{i}$ & $2.239 \mathrm{~d}-\mathrm{e}$ & $1.941 \mathrm{e}$ & $2.930 \mathrm{c}-\mathrm{f}$ & - & - & - & $1.855 \mathrm{c}-\mathrm{d}$ \\
\hline BR 18 & $1.180 \mathrm{c}-\mathrm{d}$ & 2.541 a-e & $2.875 \mathrm{~b}-\mathrm{d}$ & $2.965 \mathrm{a}-\mathrm{d}$ & $3.969 \mathrm{a}$ & $2.507 \mathrm{~b}-\mathrm{e}$ & $1.979 \mathrm{~b}-\mathrm{c}$ & $2.184 \mathrm{a}$ & $2.525 a-b$ \\
\hline IAC 24 & $527 \mathrm{~g}$ & $1.382 \mathrm{i}$ & $2.118 \mathrm{e}$ & $2.479 \mathrm{~b}-\mathrm{e}$ & $2.670 \mathrm{e}-\mathrm{f}$ & $2.156 \mathrm{~d}-\mathrm{e}$ & $1.628 \mathrm{~b}-\mathrm{e}$ & $1.413 \mathrm{~b}-\mathrm{d}$ & $1.797 \mathrm{~d}$ \\
\hline IAC $\quad 60$ & 1.159 c-e & $2.722 \mathrm{a}-\mathrm{d}$ & $3.180 \mathrm{a}-\mathrm{b}$ & $3.069 \mathrm{a}-\mathrm{c}$ & $3.541 \mathrm{a}-\mathrm{c}$ & $3.159 \mathrm{a}$ & $1.739 \mathrm{~b}-\mathrm{e}$ & $1.680 \mathrm{a}-\mathrm{d}$ & $2.531 \mathrm{a}-\mathrm{b}$ \\
\hline IAC 120 & 951 d-f & $2.812 \mathrm{a}-\mathrm{c}$ & $2.968 \mathrm{~b}-\mathrm{c}$ & 2.705 a-e & $3.618 \mathrm{a}-\mathrm{b}$ & $2.906 \mathrm{a}-\mathrm{b}$ & $2.677 \mathrm{a}$ & $1.968 \mathrm{a}-\mathrm{b}$ & $2.576 \mathrm{a}-\mathrm{b}$ \\
\hline IAC 289 & $1.194 \mathrm{c}-\mathrm{d}$ & $1.993 \mathrm{~d}-\mathrm{i}$ & 2.396 c-e & $2.524 \mathrm{~b}-\mathrm{e}$ & $3.368 \mathrm{a}-\mathrm{b}$ & $2.246 \mathrm{c}-\mathrm{e}$ & 1.510 d-e & $1.329 \mathrm{c}-\mathrm{d}$ & $2.070 \mathrm{~b}-\mathrm{d}$ \\
\hline IAC 311 & - & - & $2.406 \mathrm{c}-\mathrm{e}$ & - & - & - & - & - & $2.037 \mathrm{~b}-\mathrm{d}$ \\
\hline IAC 313 & - & - & $2.187 \mathrm{e}$ & - & - & - & - & - & $1.819 \mathrm{c}-\mathrm{d}$ \\
\hline IAC 319 & $1.488 \mathrm{~b}-\mathrm{c}$ & $2.368 \mathrm{~b}-\mathrm{f}$ & - & - & - & - & - & - & $2.429 a-b$ \\
\hline IAC 342 & - & - & $2.896 \mathrm{~b}-\mathrm{d}$ & $2.479 \mathrm{~b}-\mathrm{e}$ & $3.614 a-b$ & $2.420 \mathrm{~b}-\mathrm{e}$ & $1.923 \mathrm{~b}-\mathrm{d}$ & $1.743 \mathrm{a}-\mathrm{d}$ & $2.345 \mathrm{~b}$ \\
\hline IAC 346 & $750 \mathrm{f}-\mathrm{g}$ & $1.652 \mathrm{f}-\mathrm{i}$ & - & - & - & - & - & - & $1.703 \mathrm{~d}$ \\
\hline IAC 347 & $937 \mathrm{~d}-\mathrm{f}$ & $2.972 \mathrm{a}-\mathrm{b}$ & - & - & - & - & - & - & $2.457 \mathrm{a}-\mathrm{b}$ \\
\hline IAC 348 & 1.159 c-e & $2.236 \mathrm{c}-\mathrm{i}$ & - & - & - & - & - & - & $2.200 \mathrm{~b}-\mathrm{c}$ \\
\hline IAC 350 & $1.305 \mathrm{c}$ & $1.555 \mathrm{~g}-\mathrm{i}$ & $2.239 \mathrm{~d}-\mathrm{e}$ & 2.496 b-e & $3.833 \mathrm{a}$ & 2.712 a-e & $1.319 \mathrm{e}$ & $2.267 \mathrm{a}$ & $2.216 \mathrm{~b}-\mathrm{c}$ \\
\hline IAC 355 & - & - & $2.906 \mathrm{~b}-\mathrm{d}$ & $2.420 \mathrm{~b}-\mathrm{e}$ & $2.840 \mathrm{~d}-\mathrm{f}$ & $2.080 \mathrm{e}$ & $2.010 \mathrm{~b}-\mathrm{d}$ & $1.722 \mathrm{a}-\mathrm{d}$ & $2.162 \mathrm{~b}-\mathrm{c}$ \\
\hline IAC 356 & - & - & $2.892 \mathrm{~b}-\mathrm{d}$ & $2.618 \mathrm{~b}-\mathrm{e}$ & $3.531 \mathrm{a}-\mathrm{c}$ & $2.833 \mathrm{a}-\mathrm{c}$ & $1.989 \mathrm{~b}$ & $1.826 \mathrm{a}-\mathrm{c}$ & $2.447 \mathrm{a}-\mathrm{b}$ \\
\hline IAC 357 & - & - & $2.548 \mathrm{~b}-\mathrm{e}$ & $3.441 \mathrm{a}$ & $3.590 \mathrm{a}-\mathrm{c}$ & $2.475 \mathrm{~b}-\mathrm{e}$ & $1.520 \mathrm{c}-\mathrm{e}$ & $1.725 \mathrm{a}-\mathrm{d}$ & $2.383 \mathrm{~b}$ \\
\hline IAC 359 & - & - & - & $3.100 \mathrm{a}-\mathrm{b}$ & $3.781 \mathrm{a}$ & $2.146 \mathrm{~d}-\mathrm{e}$ & 1.597 b-d & $1.694 \mathrm{a}-\mathrm{d}$ & $2.336 \mathrm{~b}-\mathrm{c}$ \\
\hline IAC 360 & - & - & - & 2.652 a-e & $3.535 \mathrm{a}-\mathrm{c}$ & $2.753 \mathrm{a}-\mathrm{d}$ & 1.642 b-e & $1.909 \mathrm{a}-\mathrm{c}$ & $2.371 \mathrm{~b}$ \\
\hline IAC 371 & - & - & - & - & - & $2.274 \mathrm{~b}-\mathrm{e}$ & $1.975 \mathrm{~b}-\mathrm{d}$ & $1.236 \mathrm{~d}$ & $2.104 \mathrm{~b}-\mathrm{d}$ \\
\hline IAC 373 & - & - & - & - & - & $2.524 \mathrm{~b}-\mathrm{e}$ & $2.066 \mathrm{~b}$ & $1.420 \mathrm{~b}-\mathrm{d}$ & $2.279 \mathrm{~b}-\mathrm{c}$ \\
\hline IAPAR 28 & $1.451 \mathrm{~b}-\mathrm{c}$ & $2.347 \mathrm{~b}-\mathrm{g}$ & $2.514 \mathrm{c}-\mathrm{e}$ & $2.232 \mathrm{~d}-\mathrm{e}$ & $2.614 \mathrm{f}$ & - & - & - & $2.066 \mathrm{~b}-\mathrm{d}$ \\
\hline OCEPAR 14 & $1.319 \mathrm{c}$ & $2.909 a-b$ & - & - & - & - & - & - & $2.616 a-b$ \\
\hline \multicolumn{10}{|l|}{ Ciclo tardio } \\
\hline IAC 370 & - & - & - & - & $3.340 \mathrm{a}-\mathrm{d}$ & 2.590 a-e & $1.639 \mathrm{~b}-\mathrm{e}$ & $1.944 \mathrm{a}-\mathrm{b}$ & $2.322 \mathrm{~b}-\mathrm{c}$ \\
\hline IAPAR 60 & $2.104 \mathrm{a}$ & $3.284 \mathrm{a}$ & $3.614 \mathrm{a}$ & $3.135 a-b$ & 3.302 a-e & $2.166 \mathrm{~d}-\mathrm{e}$ & $2.027 \mathrm{~b}$ & $2.274 \mathrm{a}$ & $2.738 \mathrm{a}$ \\
\hline OCEPAR 16 & - & - & - & - & $2.934 \mathrm{c}-\mathrm{f}$ & $2.514 \mathrm{~b}-\mathrm{e}$ & $2.229 \mathrm{~b}$ & $1.850 \mathrm{a}-\mathrm{c}$ & $2.325 \mathrm{~b}-\mathrm{c}$ \\
\hline Médias & $1.167 \mathrm{~F}$ & $2.239 \mathrm{D}$ & $2.580 \mathrm{~B}$ & $2.665 \mathrm{~B}$ & $3.322 \mathrm{~A}$ & $2.497 \mathrm{C}$ & $1.831 \mathrm{E}$ & $1.781 \mathrm{E}$ & 2.256 \\
\hline F - Genótipos & $12.22^{* *}$ & $5.02^{* *}$ & $4.45^{* *}$ & $2.36^{*}$ & $3.86^{*}$ & $2.36^{*}$ & $4.54^{* *}$ & $2.66^{*}$ & $8.18^{* *}$ \\
\hline F - Anos & & & & & & & & & $209.84^{* *}$ \\
\hline$F-A \times G$ & & & & & & & & & $2.67^{* *}$ \\
\hline C.V.(\%) & 17.21 & 21.39 & 15.46 & 18.45 & 12.19 & 15.00 & 15.08 & 19.54 & 17.13 \\
\hline
\end{tabular}

- o genótipo não participou do experimento no referido ano.

** $\mathrm{e}^{*}$ : significativo a $1 \%$ e $5 \%$ pelo teste de $\mathrm{F}$ respectivamente.

Médias para comparação da produtividade de grãos entre cultivares por local em letras minúsculas e médias para a comparação entre locais em letras maiúsculas. Médias seguidas por letras distintas diferem entre si pelo teste de Duncan a $5 \%$. 
O estudo da estabilidade fenotípica realizado com os genótipos IAPAR 60, BR 18, IAC 120 e IAC 60 , que mostraram um comportamento diferenciado em relação aos demais quanto ao rendimento de grãos, mais IAC 350, IAC 24, IAC 289 e IAC 287 também avaliados nos oito anos considerados, revelou respostas significativas às variações ambientais tanto nos ambientes favoráveis quanto nos desfavoráveis (Tabela 5). O IAPAR 60 apresentou o quadrado médio do desvio significativo, indicativo da instabilidade no rendimento de grãos no período.

IAC 350 apresentou valores de $B_{1}+B_{2}$ superior a $1(1,8427)$ em termos de previsibilidade e o que reúne os melhores valores, responsivo à melhoria do ambiente. Os demais genótipos apresentaram $B_{1}$ muito próximos, não diferindo de 1.

A população patogênica do fungo causador da ferrugem-da-folha do trigo é dinâmica. Nota-se na tabela 6 que a ocorrência de vírus foi mais intensa nos últimos anos, talvez devido ao surgimento e à identificação de novas raças de Puccinia triticina Erikss., a partir de 1997, segundo BARCELLOS (1999).

Os genótipos Anahuac, IAC 120, IAC 356, IAC 342 e IAC 373 foram imunes a essas novas raças de ferrugem-da-folha. IAC 24 apresentou moderada resistência no ano de 2001. Esse genótipo revelou a ocorrência da doença, com progresso lento da enfermidade, ligada a uma necrose na ponta da folha da planta adulta. Segundo Rosa (1994) essa necrose é determinada pelo gene Lr 34 (resistência durável à ferrugem-da-folha) oriunda da antiga cultivar Frontana criada por Iwar Beckman em 1930.

As manchas foliares, induzidas por Bipolaris sorokiniana e Dreschslera tritici-repentis (Tabela 7), foram favorecidas pelas condições climáticas (altas temperaturas e precipitações pluviais freqüentes), e avaliadas no estádio 10.5 da escala de LARGE (1954).

A incidência desses patógenos no decorrer do período foi generalizada, sendo a mais alta ocorrida em 2001 e, em menor intensidade, em 1996. Todos os genótipos apresentaram suscetibilidade a esses fungos em maior ou menor grau de incidência, provavelmente devido ao fato de a resistência genética para fungos necrotróficos envolver muito genes (CUNFER, 1987).

Correlacionando-se as porcentagens de manchas foliares e as variáveis climáticas observadas nos oitos anos avaliados, verificou-se que houve uma correlação de $0,71^{*}$ entre a porcentagem de manchas foliares e a precipitação pluvial ocorrida em maio. Nesse mês, as plantas de trigo se encontravam no estádio final do perfilhamento e inicio do emborrachamento. De acordo com DiAz DE ACKERMANn et al. (1997) as perdas de rendimento estão muito associadas às manchas foliares, principalmente quando a infestação ocorre nessa época.

Tabela 5. Estimativa de estabilidade e adaptabilidade e coeficiente de determinação ( $\mathrm{R}$ ) para os genótipos de trigo avaliados em Capão Bonito (SP), no período de 1994 a 2001

\begin{tabular}{|c|c|c|c|c|c|c|c|}
\hline \multirow[b]{2}{*}{ Cultivar } & \multicolumn{3}{|c|}{ Médias nos ambientes } & \multirow[b]{2}{*}{$\mathrm{B}_{1}$} & \multirow[b]{2}{*}{$\mathrm{B}_{1}+\mathrm{B}_{2}$} & \multirow[b]{2}{*}{$\begin{array}{l}\text { Q. médio } \\
\text { desvio }\end{array}$} & \multirow[b]{2}{*}{$\mathrm{R}^{2}$} \\
\hline & Observada & Desfavorável & Favorável & & & & \\
\hline & 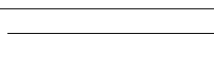 & - kg.ha ${ }^{-1}$ & 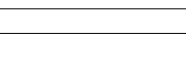 & & & kg.ha- ${ }^{-1}$ & $\%$ \\
\hline IAC 350 & 2.214 & 1.630 & 2.565 & 0,8593 & $1,8427^{*}$ & $406 n s$ & 89.51 \\
\hline IAC 24 & 1.795 & 1.189 & 2.159 & 0,9368 & 0,9712 & $304 \mathrm{~ns}$ & 86.41 \\
\hline IAC 60 & 2.530 & 1.526 & 2.132 & 1,3706 & 0,6504 & $179 \mathrm{~ns}$ & 97.01 \\
\hline IAC 120 & 2.574 & 1.865 & 3.000 & 1,1246 & 0,7725 & $375 \mathrm{~ns}$ & 84.10 \\
\hline IAC 289 & 2.069 & 1.344 & 2.504 & 0,9588 & 1,2542 & $183 \mathrm{~ns}$ & 95.41 \\
\hline IAC 287 & 2.041 & 1.441 & 2.401 & 0,8904 & 0,7388 & $147 \mathrm{~ns}$ & 95.77 \\
\hline BR 18 & 2.524 & 1.781 & 2.969 & 1,1008 & 1,4041 & $134 \mathrm{~ns}$ & 98.05 \\
\hline IAPAR 60 & 2.737 & 2.135 & 3.099 & 0,7785 & 0,3657 & $512^{*}$ & 56.15 \\
\hline
\end{tabular}

* significativo a 5\%. Fonte: Cruz, Torres e Vencovsky (1989). 
Tabela 6. Incidência médias de Puccinia triticina Erikss., fungo causador da ferrugem-da-folha em genótipos de trigo avaliados em Capão Bonito (SP), no período de 1994-2001

\begin{tabular}{|c|c|c|c|c|c|c|c|c|}
\hline Genótipos & 1994 & 1995 & 1996 & 1997 & 1998 & 1999 & 2000 & 2001 \\
\hline IAC 227 & 0 & 0 & - & - & - & - & - & - \\
\hline IAC 231 & - & - & $30 S$ & 0 & - & - & - & - \\
\hline IAC 287 & 0 & 0 & 0 & 0 & 0 & $10 S$ & $0 / 10 S$ & $10 S$ \\
\hline IAC 304 & 0 & 0 & 0 & 0 & ts & - & - & - \\
\hline IAC 332 & 0 & 0 & - & - & - & - & - & - \\
\hline IAC 340 & 0 & 0 & - & - & - & - & - & - \\
\hline IAC 354 & - & - & 0 & 0 & 0 & $10 S$ & $20 S$ & $10 S$ \\
\hline IAC 358 & - & - & $20 S$ & $10 S$ & - & - & - & - \\
\hline IAC 372 & - & - & - & - & - & $20 S$ & $10 S$ & $20 S$ \\
\hline Panda & 0 & $10 S$ & - & - & - & - & - & - \\
\hline Anahuac & 0 & 0 & 0 & 0 & 0 & - & - & - \\
\hline BR 18 & 0 & 0 & 0 & 0 & 0 & 0 & $5 \mathrm{MR}$ & 0 \\
\hline IAC 24 & 0 & 0 & 0 & 0 & 0 & $20 \mathrm{MS}$ & $0 / 5 S$ & $10 \mathrm{MR}$ \\
\hline IAC 60 & 0 & 0 & 0 & 0 & 0 & 0 & $10 \mathrm{MS}$ & 0 \\
\hline IAC 120 & 0 & 0 & 0 & 0 & 0 & 0 & 0 & 0 \\
\hline IAC 289 & 0 & 0 & $10 S$ & 0 & 0 & $10 S$ & $0 / 20 S$ & $10 S$ \\
\hline IAC 311 & - & - & 0 & - & - & - & - & - \\
\hline IAC 313 & - & - & 0 & - & - & - & - & - \\
\hline IAC 319 & 0 & 0 & - & - & - & - & - & - \\
\hline IAC 342 & - & - & 0 & 0 & 0 & 0 & 0 & 0 \\
\hline IAC 346 & 0 & 0 & - & - & - & - & - & - \\
\hline IAC 347 & 0 & ts & - & - & - & - & - & - \\
\hline IAC 348 & 0 & 0 & - & - & - & - & - & - \\
\hline IAC 350 & 0 & 0 & 0 & 0 & 0 & $10 S$ & $20 / 40 S$ & $10 S$ \\
\hline IAC 355 & - & - & 0 & 0 & 0 & 0 & $0 / 20 S$ & 0 \\
\hline IAC 356 & - & - & 0 & 0 & 0 & 0 & 0 & 0 \\
\hline IAC 357 & - & - & 0 & 0 & 0 & $30 S$ & $30 S$ & $10 S$ \\
\hline IAC 359 & - & - & - & 0 & 0 & $10 S$ & $20 S$ & $10 S$ \\
\hline IAC 360 & - & - & - & 0 & 0 & $10 S$ & $30 S$ & $30 S$ \\
\hline IAC 371 & - & - & - & - & - & $20 S$ & $10 S$ & $30 S$ \\
\hline IAC 373 & - & - & - & - & - & 0 & 0 & 0 \\
\hline IAPAR 28 & 0 & 0 & $10 S$ & 0 & 0 & 0 & - & - \\
\hline OCEPAR 14 & 0 & 0 & - & - & - & - & - & - \\
\hline IAC 370 & - & - & - & - & 0 & 0 & $20 S$ & $\mathrm{~T}$ \\
\hline IAPAR 60 & 0 & 0 & 0 & 0 & 0 & $10 \mathrm{MR}$ & $20 \mathrm{MR}$ & 0 \\
\hline OCEPAR 16 & - & - & - & - & 0 & 0 & $0 / 10 \mathrm{~S}$ & 0 \\
\hline
\end{tabular}

S - suscetível; MS - moderadamente suscetível; MR - moderadamente resistente; R - resistente.

Fonte: Anikster et al. (1997). 
Tabela 7. Incidência médias de manchas foliares em porcentagem causadas pela associação dos fungos necrotróficos como Bipolaris sorokiniana e Drecheslera tritici repentis nos genótipos de trigo avaliados em Capão Bonito (SP), no período de 1994-2001

\begin{tabular}{|c|c|c|c|c|c|c|c|c|}
\hline Genótipos & 1994 & 1995 & 1996 & 1997 & 1998 & 1999 & 2000 & 2001 \\
\hline IAC 227 & 20 & 20 & - & - & - & - & - & - \\
\hline IAC 231 & - & - & 10 & 40 & - & - & - & - \\
\hline IAC 287 & 30 & 20 & 10 & 40 & 30 & 30 & 40 & 30 \\
\hline IAC 304 & 40 & 20 & 20 & 40 & 40 & - & - & - \\
\hline IAC 332 & 30 & 30 & - & - & - & - & - & - \\
\hline IAC 340 & 40 & 20 & - & - & - & - & - & - \\
\hline IAC 348 & 30 & 20 & - & - & - & - & - & - \\
\hline IAC 354 & - & - & 20 & 30 & 40 & 30 & 40 & 50 \\
\hline IAC 358 & - & - & 20 & 40 & - & - & - & - \\
\hline IAC 372 & - & - & - & - & - & 20 & 20 & 30 \\
\hline Panda & 20 & 20 & - & - & - & - & - & - \\
\hline Anahuac & 30 & 30 & 10 & 40 & 30 & - & - & - \\
\hline BR 18 & 30 & 20 & 20 & 40 & 40 & 30 & 20 & 50 \\
\hline IAC 24 & 50 & 30 & 20 & 40 & 40 & 30 & 20 & 40 \\
\hline IAC 60 & 30 & 20 & 20 & 30 & 30 & 30 & 20 & 40 \\
\hline IAC 120 & 30 & 20 & 20 & 30 & 30 & 40 & 20 & 30 \\
\hline IAC 289 & 30 & 40 & 20 & 30 & 30 & 30 & 20 & 40 \\
\hline IAC 311 & - & - & 20 & - & - & - & - & - \\
\hline IAC 313 & - & - & 10 & - & - & - & - & - \\
\hline IAC 319 & 30 & 30 & - & - & - & - & - & - \\
\hline IAC 342 & - & - & 20 & 40 & 30 & 30 & 40 & 30 \\
\hline IAC 346 & 50 & 20 & - & - & - & - & - & - \\
\hline IAC 347 & 30 & 20 & - & - & - & - & - & - \\
\hline IAC 350 & 30 & 50 & 30 & 30 & 30 & 30 & 20 & 30 \\
\hline IAC 355 & - & - & 20 & 30 & 30 & 40 & 40 & 50 \\
\hline IAC 356 & - & - & 20 & 30 & 30 & 30 & 10 & 50 \\
\hline IAC 357 & - & - & 10 & 30 & 30 & 30 & 20 & 30 \\
\hline IAC 359 & - & - & - & 40 & 40 & 30 & 40 & 50 \\
\hline IAC 360 & - & - & - & 40 & 40 & 30 & 40 & 40 \\
\hline IAC 371 & - & - & - & - & - & 30 & 30 & 50 \\
\hline IAC 373 & - & - & - & - & - & 30 & 20 & 50 \\
\hline IAPAR 28 & 30 & 40 & 20 & 40 & 30 & - & - & - \\
\hline OCEPAR 14 & 30 & 10 & - & - & - & - & - & - \\
\hline IAC 370 & - & - & - & - & 30 & 30 & 20 & 30 \\
\hline IAPAR 60 & 20 & 10 & 20 & 30 & 40 & 30 & 30 & 30 \\
\hline OCEPAR 16 & - & - & - & - & 30 & 30 & 30 & 60 \\
\hline
\end{tabular}




\section{CONCLUSÕES}

1. Os genótipos mostraram comportamento diferenciado quanto ao rendimento de grãos apesar da interação genótipos $x$ anos.

2. O genótipo IAPAR 60 apresentou maior rendimento de grãos não diferindo de BR 18, IAC 60 e IAC 60 na média dos oito anos analisados. IAPAR 60 mostrou instabilidade no rendimento de grãos no período.

3. Os genótipos demonstraram possuir resistência genética à ferrugem-da-folha, com destaque para IAC 120, IAC 356, IAC 342, IAC 373 e Anahuac. $\mathrm{O}$ mesmo não ocorreu com relação às manchas foliares.

4. As precipitações pluviais ocorridas em maio foram as que melhor se correlacionaram com o aparecimento de manchas foliares.

\section{AGRADECIMENTOS}

Aos técnicos de apoio Carlos Aparecido Fernandes, José Norberto da Silva e José Angelino de Paula, pela colaboração no desenvolvimento dos experimentos.

\section{REFERÊNCIAS}

AACC. AMERICAN ASSOCIATION OF CEREAL CHEMISTS. Approved methods of AACC. 9.ed. St. Paul, 1995.

ANIKSTER, Y.; BUSHNELL, W.R.; EILAM, T.; MANISTERSKI, J.; ROELFS,A.P. Puccinia recondita causing laef rust on cultivated wheats, wild wheats, and rye. Canadian Journal of Botany, Ottawa, v.75, n.12, p.2082-2086, 1997.

BARCELLOS, A.L. A ferrugem-do-trigo no Brasil. In: FUNDAÇÃO CARGILL. Trigo no Brasil. Campinas, 1982. v.2, p.377-410

BARCELLOS, A.L. População patogênica de Puccinia triticina (Ferrugem-da-folha do trigo) no período 1997-1999. In: REUNIÃO NACIONAL DE PESQUISA DE TRIGO, 18., 1994, Passo Fundo. Resumos. Passo Fundo: CNPT, 1999. v.2, p.524-528

BRAMMER, S.P.; BARCELLOS, A.L.; MORAES-FERNADES, M.I.B.; MILACH, S.C.K. Bases genéticas da resistência durável à ferrugem da folha do trigo e estratégias biotecnológicas para o melhoramento no Brasil. Fitopatologia Brasileira, Brasília, v.25, n.1, 2000. p.5-20.

BRASIL. Instrução Normativa n. ${ }^{\circ}$ 7, de 15/8/2001. Ministério da Agricultura e do Abastecimento. Diário Oficial da União, n.160. seção 1.21/8/ 2001.
CRUZ, C.D.; TORRES, R.A.; VENCOVSKY, R. An altenative approach to the stability analysis proposed by Silva e Barreto. Revista Brasileira de Genética, Ribeirão Preto, v.12, p.567-580, 1989.

CUNFER, B.M. Bacterial and fungal blights of the foliage and heads of wheat. In HEYNE, E.G. (Ed). Wheat and Wheat Improvement. 2.ed. Madison: American Society of Agronomy, 1987. p.528-541.

DÍAZ de ACKERMANN, M.; KOHLI, M.M.; CERETTA, S.; ABADIE, T.; IBÁNEZ, V. Importancia de las enfermedades en la producción del trigo en Uruguay. In: KOHLI, M. M.; MARINO, D. (Eds.). Explorando altos rendimientos de trigo. La Estanzuela, Uruguay: CIMMYT-INIA,1998. p.261-278.

DIAZ, R.; ABADIE, T. Rendimiento potencial y brechas tecnológicas de trigo em el Urugauy y en el Cone Sur. In: KOHLI, M. M. y MARINO, D. (Eds.). Explorando altos rendimientos de trigo. La Estanzuela, Uruguay: CIMMYTINIA, 1998. p.1-20.

FELICIO, J.C.; CAMARGO, C.E.O.; PEDRO JUNIOR, M. J. Avaliação de genótipos de trigo no Vale do Paranapanema (SP) de 1985 a 1991. Bragantia, Campinas, v.52, n.1, p. 33-44, 1993.

FELICIO, J.C.; CAMARGO, C.E.O.; GERMANI, R.; FREITAS, J.G.; FERREIRA FILHO, A.W.P. Rendimentos de grãos e qualidade tecnológica de genótipos de trigo em três zonas tritícolas do Estado de São Paulo no biênio 1994-95. Bragantia, Campinas, v.59, n.1, p.59-68, 2000.

INSTITUTO AGRONÔMICO (CAMPINAS). Recomendações Técnicas de Trigo para 1999. 2.ed.atual. Campinas, 1999. 100p.

LARGE, E.C. Growth stages in cereals: Ilustration of the Feekes Scale. Plant Pathology, London, v.3, p.128-129. 1954.

METHA, Y.R. Doenças do trigo e seu controle. São Paulo: Agronômica Ceres, 1978. 190p. (Ceres, 20)

PICININI, E.C.; FERNANDES, J.M.C. Efeito de diferentes fungicidas sobre o rendimento de grãos, sobre o peso do hectolitro e sobre o controle da ferrugem da folha (Puccinia recondita f.sp. tritici) em trigo, cultivar BR 43. Fitopatologia Brasileira, Brasília, v.20, p.319, 1995. (Suplemento)

PICININI, E.C.; FERNANDES, J.M.C. Controle das doenças de trigo. In: CUNHA, G.R.; BACALTCHUK, B. (Eds.). Tecnologia para produzir trigo no Rio Grande do Sul. Porto Alegre: Assembléia Legislativa, Comissão de Agricultura, Pecuária e Cooperativismo/ Passo Fundo: Embrapa Trigo, 2000. p.225-243. (Série Culturas, 02)

PIMENTEL-COMES, F. Curso de estatística experimental. 13.ed. Piracicaba: Nobel, 1970. 468p.

RAIJ, B. van; CANTARELLA, H.; QUAGGIO, J.A.; FURLANI, A..M. (Eds.). Recomendações de Adubação e calagem para o Estado de São Paulo. Campinas: IAC/Fundação IAC, 1996. 285p. (Boletim técnico, 100). 
RODRIGUES, O. Manejo de trigo: bases ecofisiológicas. In: CUNHA, G.R.; BACALTCHUK, B. (Eds.). Tecnologia para produzir trigo no Rio Grande do Sul. Porto Alegre: Assembléia Legislativa, Comissão de Agricultura, Pecuária e Cooperativismo/Passo Fundo: Embrapa Trigo, 2000. p.120155. (Série Culturas, n. 02)

ROSA, O. Teoria sobre a origem da resistência durável à ferrugem da folha de cultivares brasileiras de trigo. In: REUNIÃO NACIONAL DE PESQUISA DE TRIGO, 17., 1994, Passo Fundo. Resumos. Passo Fundo: CNPT, 1994. p.153.
SCHARAMM, W.; FULCO, W.S.; SOARES, M.H.G.; ALMEIDA, A.M.P. Resistência de cultivares de trigo em experimentos ou cultivo no Rio Grande do Sul, às principais doenças fúngicas. Agronomia Sulriograndense, Porto Alegre, v.10, p.31-39, 1974.

WAL, P. C. Rendimientos y el cociente fototérmico Una relación inevitable? In: KOHLI, M.M.; MARINO, D. (Eds.). Explorando altos rendimientos de trigo. La Estanzuela, Uruguay: CIMMYT-INIA, 1998. p.47-58. 